\title{
Research on Risk Prevention of "Shared Employees" Model Under the Background of Public Health Emergencies
}

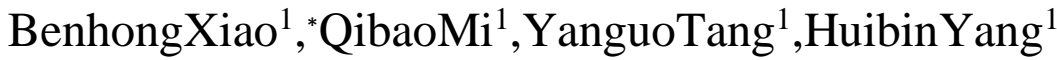 \\ ${ }^{1}$ Pan-Asia Business School, Yunnan Normal University. Kunming, Yunnan, 650092 \\ *Corresponding author. Email: 1056472207@qq.com
}

\begin{abstract}
During the outbreak of Novel Coronavirus Pneumonia in 2020, on the one hand tourism, catering, hotel, entertainment, film and television and other service industries are greatly affected, and a large number of employees are waiting to return to work, resulting in "labor difficulty". On the other hand, there is a "labor shortage" in new retail industries such as fresh HEMA and meituan takeout. As a result, enterprises with" difficult employment"will " lease"their employees to"labor shortage enterprises, and these "leased employees" are called"shared employees".The employment mode of " sharing employees"alleviates the problems of labor shortage and difficult enterprises, enlivens human resources, increases employment, and promotes social harmony and stability. However, there are many risks in this new employment mode, but there are also many risks in this new employment mode Based on the analysis of the existing risks, this paper puts forward some countermeasures and suggestions from several aspects to promote the standardization of this employment mode and reduce employment disputes.
\end{abstract}

Keywords: COVID-19 epidemic, shared employees, risk prevention

\section{突发公共卫生背景下 “共享员工” 模式 风险防范研究}

\section{肖本红 ${ }^{1}{ }^{*}$ 密其宝 ${ }^{1}$ 汤晏国 ${ }^{1}$ 杨慧宾 ${ }^{1}$}

${ }^{1}$ 云南师范大学泛亚商学院 云南 昆明 650092

“通讯作者. 电子邮箱: 1056472207@qq.com

\section{摘要}

2020 年新冠肺炎疫情期间，一方面旅游、餐饮、酒店、娱乐、影视等服务业受到较大影响，大批员工等待复 工, 出现了 “用工难” 的情况, 另一方面盒马生鲜、美团外卖等新零售行业出现了 “用工荒” 。于是, “用工 难” 的企业将员工 “出租” 给 “用工荒” 的企业，这些 “被出租的员工” 称为 “共享员工”。“共享员工” 的 用工方式, 缓解了用工荒与用工难企业的难题、盘活了人力资源, 也增加了就业, 促进了社会和谐稳定。但针 对这一新的用工模式，也存在着诸多风险。本文在分析了存在的风险的基础上，从几个方面提出了一些对策建 议, 促进这一用工模式的规范化, 减少用工纠纷。 
关键词：新冠疫情，共享员工，风险防范

\section{1. 引言}

2020 年新冠肺炎疫情期间，一方面旅游、餐饮、 酒店、娱乐、影视等服务业受到较大影响，大批员工 等待复工, 另一方面盒马生鲜、美团外卖等新零售行 业却出现了用工告急。据报道, 盒马生鲜与云海有、 西贝、探鱼、青年餐厅等餐饮品牌达成 “共享员工” 的合作，短期入职人数超过 1800 人，随后，京东便 利店 7FRESH、沃尔玛、阿里等也推出共享员工 ${ }^{[1]}$ 。为 了盘活闲置的人力资源、最大化地优化人力资源配置, 市场自发地催生出了“不为所有、但为我用的” 的 “共 享员工” 的用工方式。

\section{2. 什么是 “共享员工” 用工模式}

\section{1 “共享员工”（SHARING EMPLOYEE）概念}

这一术语是借用共享单车、共享汽车等互联网背 景下产生的一个新名词。何永贵, 姜莎莎认为共享员 工 “是将员工以共享模式进行短期人力输出的合作用 工模式。这种用工模式使得企业和企业之间以“借用” 或 “外派” 的方式实现劳动力的流动, 实现人力成本 转化为人力资本, 进行人力资源的再分配, 使得市场 资源配置更合理” ${ }^{[2]}$ 。市良、曹艳梅认为员工共享即 “用工荒的企业 (用工企业) 临时租用停业餐饮等传 统企业（用人企业）中的待岗员工（共享员工），共 享员工在用工单位从事非全日制、临时性和弹性工作 的就业状态。” ${ }^{[3]}$ 当然, 这些概念并非严谨, 一是 “临 时租用” 并非规范用语, 从法律上讲, 租用的标的物 应该为某种物体, 带有 “人身” 性质的员工并不能租 用。二是, 从实际用工来看, 共享员工并非在用工单 位仅从事非全日制、临时性和弹性工作，从事全日制、 长期性和固定性的工作的员工逐渐增多。简单地说, “共享员工” 是指几个企业在不同的时间段共用一个 员工、一个员工在不同的时间段为几个企业提供服务， 又称为 “员工共享”。

\section{2 “共享员工” 用工模式的特点}

一是用人单位不用工。用人单位与劳动者签订劳 动合同, 依法购买医疗、养老、工伤等各种社会保险, 形成法律上的劳动关系。但由于疫情的影响, 用人单 位无法复工或部分复工, 造成全部或部分劳动者无工 可做, 处于待业状态, 何时复工仍具有不确定性。但 如果不输出员工，与其他企业共享，在员工待业期间 仍需为员工购买各种社会保险, 并每月支付员工一定 的生活费。在员工共享期间形成了事实上的用人单位 不用工。

二是用工单位不用人。用工单位不与劳动者签订 劳动合同, 也不购买医疗、养老、工伤等各种社会保 险, 不形成法律上的劳动关系。但由于疫情的影响, 快递、外卖等电商行业需要大量用工，但这种用工具 有临时性和时间长短的不确定。但如果不借用其他企 业的员工, 实行员工共享, 就需要与员工签订劳动合 同、建立劳动关系, 购买社会保险, 等疫情结束后造 成工人闲置。实行员工共享的用工模式，无需为员工 购买各种社会保险，仅仅按工作时间支付一定的工资 即可。形成了事实上的用工单位不用人。

三是具有临时性与不确定性。由于新冠疫情这种 具有公共突发卫生事件何时发生、如何发展、何时结 束、国家或者区域防控程度的不同等具有不确定性, 使得共享员工的共享期也具有不确定性, 共享员工所 从事的多为临时性、短期性的工作，也有一些从事长 期性、固定性的工作。但正常来说，一旦 “共享员工” 的条件消失后即回归正常的用工模式。

四是多方互利共赢。这一用工模式可谓是特殊时 期企业间的临时救济措施，共同 “抱团取暖，共同难 关”。第一, 缓解了用工单位的用工荒, 还支付了比 正常用人较低的工资，降低经营成本；第二，盘活了 用人单位闲置的人力资源, 减轻了用人单位停产歇业 期间仍需支付待业员工不低于当地最低工资标准的 开支; 第三，增加了社会就业，有利于社会的和谐稳 定。 


\section{3 “共享员工” 的性质}

在国外，这一用工模式被称为灵活就业 (Flexible employment), 而且具有较长的历史和 较大的普遍性, 大多集中在有淡旺季的服务行业中, 如餐饮业、旅游业等。“据公开资料显示, 2019 年, 日本企业界灵活用工率已高达 49\%，美国紧随其后 达到 $42 \%$ 。” 年在我国, 这一灵活的用工模式实践上 也早已出现,如“2016 年河南能化旗下焦煤、义煤、 鹤煤就曾借调人员帮助富士康扩产能 。” ${ }^{[5]}$ “其实, 这同长期以来一些大型连锁超市、规模较大的集团制 企业中本已存在的借调现象类似, 只是用了一个更新 的概念，其本质上仍是灵活用工的一种方式。” ${ }^{66}$

我国法律规定的灵活用工模式主要有劳务派遣、 业务外包、劳务用工 (雇佣关系) 、退休人员返聘等, 目前对共享员工这一用工模式还未有明确的规定。但 由于这种模式具有多方共赢的特点, 符合人力资源配 置的最大化原则, 未来这种模式有可能为越来越多的 企业采用。从用工性质上来看, 劳动者与用人单位维 持原有的劳动关系, 主要受《劳动法》和《劳动合同 法》的调整; 劳动者与用工单位是劳务关系, 主要受 民事法律调整, 目前是《民法通则》《民法总则》调 整， 2021 年 1 月 1 日起则为《民法典》调整; 用人 单位与用工单位之间, 通过双方签署合作协议或借用 协议, 将用人单位闲置待工的员工派出或借出至用工 单位使用, 不与用工单位建立劳动关系, 劳动者遵守 用工单位的劳动管理, 用人单位与用工单位之间建立 的是平等主体间的民事合同关系，主要受民法调整， 由于用人单位不具有劳务派遣资质, 一般不向用工单 位收取管理费, 由用工单位之间向劳动者支付工资。

\section{3. “共享员工” 用工模式存在的风险}

针对这一新的用工模式, 看似一石多鸟, 有百利 而无一害, 实际上对用人单位、用工单位和员工都蕴 含着诸多的风险。

\section{1 合同方面的风险}

（1）不签合同的风险。虽然法律没有禁止性的 规定, 这种用工模式不违法, 但同时法律对这一用工
模式也没有明确的规定，实践中，用人单位与用工单 位之间也会采用口头约定或者默认的方式实行 “共享 员工”，不签定任何合同，一旦发生纠纷，处理起来 较为麻烦。

（2）用工单位直接与员工签订合同的风险。实 践中, 存在停产歇业的员工绕过用人单位或者不经用 人单位许可, 直接与用工单位签订短期合同或者不签 合同。实际上，这可以理解为员工私自的兼职行为, 用人单位并不知情或者 “佯装不知”。但用工单位与 员工形成事实上的 “共享员工”, 形成是劳务关系。 但若对用人单位造成损失, 员工与用工单位需承担连 带赔偿责任。另一方面, 若员工因此违反用人单位的 规章制度, 受到处罚或解除劳动合同的, 员工和用工 单位也可能承担一定的风险。

\section{2 变相劳务派遗的风险。}

实践中，为了便于工资发放，用工单位将应付的 工资发给用人单位，由用人单位再将工资支付给员工， 用人单位收取一定的管理费。或者疫情结束后，用人 单位仍然派出员工, 将疫情下的临时行为变为长期的 做法, 变相实行劳务派遣。由于其没有劳务派遣资质, 违反劳动派遣的有关法律规定。

\section{3 员工保障的风险}

（1）最低工资保障、带薪休假等违反法律规定 的风险。实践中，存在用人单位与用工单位各发一部 分工资的情况，由于缺乏充分的沟通，两部分工资并 在一起有可能低于当地最低工资支付标准的问题、也 可能存在个人所得税缴纳不准确的问题。此外, 也存 在共享员工带薪休假如何休，休假期间工资由哪方支 付的问题。

（2）员工自身受到伤害的风险。如上下班途中 意外受到伤害、生产经营中受伤能否适用工伤保险。

“从形式上判断, 目前用工需求企业与这些员工之间 的关系性质仅仅只是劳务关系，因工受伤时也难以适 用工伤保险待遇”。

\section{4 竞业限制与商业秘密泄露的风险。}

有些共享员工属于竞业限制的范围, 迫不得已的 
情况下共享到用工单位，有可能违反竞业限制的规定; 此外, 也存在将用人单位的商业秘密泄露给用工单位 的风险, 或者将用工单位的商业秘密泄露给用人单位 的风险, 特别容易发生在是两个企业性质相近之间的 共享。

\section{5 共享员工不能被“召回” 的风险。}

共享期满后, 由于用工单位的薪酬福利、工作环境 等原因, 存在共享员工更倾向于留在用工单位, 不再 回到原用人单位的情况。

\section{4. 防范 “共享员工”用工模式风险的对策建议}

（1）树立风险意识。市场经济本质上是契约经 济, 契约就存在诸多的权利、义务, 存在契约履行中 的风险, 共享员工模式是市场经济下人力资源优化配 置的产物, 具有多重的契约关系。面对这一新的用工 模式, 相关法律法规还不完善, 只有提高风险意识, 学习有关法律, 才能减产或避免法律风险。

（2）用人单位与用工单位签订协议。可以是合 作协议将员工派出到用工单位, 也可以是借用合同将 员工借用到用工单位, 但不得以营利为目的。协议中 要明确双方的责任义务, 如工资支付 (用工单位直接 发放、或是由用工单位转给用人单位发放）、劳动保 障、安全事项、意外风险、合作期限、竞业限制、商 业秘密、员工召回条件等。但无论是何种协议都不得 违反法律规定, 变相变成实质上的劳务派遣合同。

（3）加强入职培训。减少工资中的各种风险、 尽快适应新工作、入职培训。共享员工进入的大多是 与原本行业工作完全不同的企业, 因为对新的工作不 熟悉, 也没有一定的工作经验, 一些高门槛的或者必 须具备相应能力的工作不能很快的上手, 这就决定了 共享员工只能承担较简单机械的事务性工作, 这种工 作培训时间短，容易在短时间内轻松上岗。

（4）购买商业保险。减少意外伤害风险。每个 共享员工购置人身意外保险或者购买短期的雇主责
任险, 这些举措都大大降低用工中的风险, 充分保障 员工利益, 增加员工的归属感, 进而激励员工努力工 作。

（5）加强立法、提供政策支持。从国家和社会 层面。目前, 共享员工有不断扩大的趋势, 从临近行 业的共享逐渐扩大到款行业、跨区域的共享，也出现 了 “员工共享” 的电商平台。政府应顺势而为, 制定、 完善相关法律法规，调整、引导这种模式有序发展， 不但有效解决和避免劳动纠纷、保护员工合法权益, 促进社会和谐。

总之，“共享员工”这一灵活的用工模式在我国 社会实践中几年前已有尝试, 只不过在新冠肺炎这一 突发公共卫生事件下尤为凸显，由于它激活了闲置的 人力资源，最大化地通过市场配置人力资源，节省了 用工成本。可以预见，即使疫情过后这种用工模式也 有存在的市场，可谓方兴未艾。我们只有正确认识， 加强规范，防范风险，才能使之走得更远。

参考文献:

[1]刘爻寒，共享员工倒逼灵活用工新探索 $[J]$ ， 中国新时代，2020.4：109-110.

[2]杨琴，对特殊时期 “共享员工” 的几点思考 [J]，劳动经济，2020（11），100.

[3] 姜颖：厘清各方权利义务让共享员工模式走 得更远 [M]，法制日报, 2020 年 4 月 15 日 05 版.

[4] 陈施言，向征．浅议突发公共卫生事件下 “共享员工” 模式的现状及发展 $[\mathrm{J}]$ 。现代管理, 2020, 10 (2) : 306 .

[5]He Yonggui, Jiang Shasha. Research on Enterprise Human Resource Management Mode Based on New Business Sharing Economy [J]. Management modernization, 2020, 40(1) : 56-59

[6]市良、曹艳梅, 新冠病毒疫情下 “员工共享” 模式的法律思考, 法制与社会 $[J], 2020.4$ (上) : 41 